\title{
Chickenpox Mimicking Monkeypox in Adult with Diabetes Mellitus and Acute Kidney Injury: Diagnosis and Management
}

\author{
Maya Wardiana, Rahmadewi, Dwi Murtiastutik, Sawitri, Damayanti \\ Department of Dermatology and Venereology \\ Faculty of Medicine Universitas Airlangga/Dr. Soetomo General Academic Hospital
}

\begin{abstract}
Background: Chickenpox caused by the varicella-zoster virus (VZV) in diabetes mellitus patients might exhibit similar clinical features with monkeypox, caused by monkeypox virus (MPXV). In May 2019, Singapore notified World Health Organization (WHO) of one laboratory-confirmed case of monkeypox. Considering Singapore is located near Indonesia, awareness about the possibility of an outbreak in Indonesia should be raised. Purpose: To report a case of chickenpox mimicking monkeypox in an adult with diabetes mellitus and acute kidney injury. Case: A 51-year-old male with poorly controlled diabetes mellitus was suspected to have a chickenpox differential diagnosis with monkeypox. His chief complaint was multiple blisters on his body and vomiting. There was a history of feeding a monkey. From dermatological status on facial, trunk, and extremities there were multiple pleomorphic vesicles. Laboratory results showed elevated renal function. Polymerase chain reaction (PCR) examination using VZV as primer revealed a positive result in the range of $810 \mathrm{bp}$. He was treated with intravenous acyclovir for 3 days and oral acyclovir for 7 days then discharged with improvement in skin lesions and normal renal function. Discussion: Chickenpox in adult and diabetes mellitus patients can give severe clinical manifestation mimicking monkeypox. PCR has a significant role especially when diagnosis could not be established from the physical examination. Acyclovir can be given as the therapy. Conclusion: Adult and poorly controlled diabetes mellitus are important risk factors associated with the severity and complication of chickenpox. A careful diagnostic approach and management are needed.
\end{abstract}

Keywords: chickenpox, monkeypox, diabetes mellitus, acute kidney injury, PCR.

Correspondence: Rahmadewi, Department of Dermatology and Venereology, Faculty of Medicine, Universitas Airlangga/Dr. Soetomo General Academic Hospital, Mayjen Prof. Dr. Moestopo Street No. 6-8 Surabaya 60131, Indonesia. Phone: +6231 5501609, e-mail: dewimbo@yahoo.co.id.

Article info | Submited: 11-3-2020, Accepted: 27-4-2020, Published: 30-11-2021

\section{BACKGROUND}

Chickenpox or varicella is an acute highly contagious disease caused by the primary infection of varicella-zoster virus (VZV). VZV is a member of the herpes virus family and exclusively a human neurotropic alpha-herpesvirus subfamily. Chickenpox is characterized by a self-limiting rash on the skin and sometimes mucosa. The rash begins as macules, rapidly progress to papules, followed by a vesicular stage and crusting of lesions. In common practice, chickenpox is often diagnosed only from clinical features, by the appearance and evolution of the rash, particularly when there is contact history within 2 to 3 weeks before. ${ }^{1,2}$

Chickenpox is distributed worldwide, but it seems temperate and tropical climate also affect the agespecific incidence. In a temperate climate, age-specific chickenpox incidence is highest in preschool-aged children or children in early elementary school with an annual incidence of greater than 100 per 1,000 children. In tropical climates, acquisition of chickenpox occurs at a higher overall mean age (for example, at 14.5 years in Sri Lanka), with a higher proportion of cases in adults. ${ }^{3}$ Chickenpox or varicella vaccinations also affect the incidence of chickenpox. From 1988 to 1995 , before the varicella vaccine was introduced, there were approximately 11,000 hospitalizations and 100 deaths caused by varicella each year in the United States. Two-dose varicella vaccine coverage in the United States now exceeds $90 \%$ in young children. This has resulted in a marked reduction in varicella-related morbidity. ${ }^{2}$

Patients with diabetes mellitus have significantly lower cellular mediated immunity than healthy individuals. ${ }^{4}$ This condition could make chickenpox in individuals with diabetes mellitus show more severe clinical manifestations that might exhibit similar clinical features with poxvirus diseases, such as monkeypox and smallpox. The smallpox which is caused by the variola virus, a member of the poxviridae 
family, is now declared eradicated in 1980 following a global immunization campaign led by the World Health Organization (WHO). The last known natural case was in Somalia in $1977 .^{5}$

Monkeypox, on the other hand, is an emerging zoonotic disease caused by the monkeypox virus (MPXV). It is also a member of the poxviridae family. It is transmitted when a person comes into contact with a virus from an animal, human, or material contaminated with the virus. The virus enters the body through broken skin (even if not visible), respiratory tract, or mucous membranes (eyes, nose, or mouth). Transmission from animal to human may occur by bite or scratch, bush meat preparation, direct contact with body fluids or lesion material, or indirect contact with lesion material, such as through contaminated bedding. ${ }^{6}$ Human-to-human transmission is potential regarding large monkeypox outbreak that occurred in Nigeria in 2017-2018. ${ }^{7}$ A study in the Democratic Republic of Congo (formerly Zaire) showed that among 730 patients diagnosed as cases of chickenpox, $3.3 \%$ had monkeypox by diagnostic testing. ${ }^{8}$ The first human case of monkeypox was recorded in 1970 in the Democratic Republic of the Congo during a period of intensified effort to eliminate smallpox. ${ }^{6}$ Since 2010, monkeypox has expanded to cause outbreaks among humans in seven additional African countries: Cameroon, Central African Republic, Republic of the Congo, Liberia, Nigeria, Sierra Leone, and South Sudan. Complications of monkeypox included secondary bacterial infections, respiratory distress, bronchopneumonia, gastrointestinal involvement, dehydration, sepsis, encephalitis, and corneal infection with ensuing loss of vision. The case fatality rate for monkeypox is $10 \%$, lies between the case fatality rate of variola (or smallpox) major (30\%) and variola minor $(1 \%){ }^{7}$

Recently on May, $9^{\text {th }} 2019$, the Ministry of Health in Singapore notified WHO of one laboratoryconfirmed case of monkeypox. The case patient was a 38 years old Nigerian man who arrived in Singapore on April 2019. ${ }^{8}$ Considering that Singapore is located near to Indonesia and the mobility of travelers between these countries is high, awareness about the possibility of an outbreak in Indonesia should be raised. Hence, a careful diagnostic approach becomes important to distinguish chickenpox from monkeypox and vice versa.

\section{CASE REPORT}

In June 2019, a 51-year old male was consulted by Internal Division to Dermatology and Venereology Division suspected of chickenpox with differential diagnosis of monkeypox. He was referred from a private hospital. His chief complaint was multiple blisters almost all over his body. He complaint about multiple blisters almost all over his body that worsens in the last 3 days before referral. The blisters were mainly on the face and upper body. It is accompanied by an itchy sensation. He also complaint about nausea and vomiting. Just before referral, he vomited twice. This patient has been hospitalized in a private hospital for 3 days before he was referred to Dr. Soetomo General Academic Hospital. In that hospital, he got an injection of antipyretic and antiemetic.

Before the blisters appeared, this patient complaint about muscle sore, malaise, and fever 1 week before, followed by blisters appearance. It initially appeared on the head and then it spread. He took medicine and vitamin from primary health care, but he did not get better. The patient's son had chickenpox 2 weeks before the patient's complaint. There was a history of feeding a monkey 1 week before that belong to the patient's neighbor, but he did not have a complaint. This patient has diabetes mellitus since 2011. He consumed glibenclamide as an oral antidiabetic, but he rarely checked his blood sugar status. The history of traveling overseas or eating primate meat was denied. This patient never has chickenpox nor varicella vaccination before. The history of taking traditional medicine, hypertension, drug allergy, asthma, or rhinitis allergy were denied.

From the physical examination, his general status was weak with a body weight of 75 kilograms. From vital sign measurement, his blood pressure was 139/76 $\mathrm{mmHg}$, heart rate was 102 times per minute, respiratory rate was 16 times per minute and his temperature was $36,6^{\circ} \mathrm{C}$. There was no lymph node enlargement on the cervical, axillary, or inguinal. From dermatological status, on facial region there were multiple pleomorphic vesicles (multiple stages of development) and multiple crusts, on trunk and extremities superior et inferior region, there were multiple pleomorphic vesicles (multiple stages of development), some of them with umbilication, with the centripetal distribution. Figure 1 show the clinical skin manifestation of the patient.

In collaboration with Internal Division, several laboratory examinations such as complete blood count, blood glucose test, HbA1C measurement, liver, and renal function test, lipid profile, and serum electrolyte were done. Laboratory examination revealed: hemoglobin level was $12.5 \mathrm{~g} / \mathrm{dL}$, red blood cells were $4.48 \times 106 / \mathrm{uL}$, white blood cells was $6,870 / \mathrm{uL}$, platelet was $125,000 / \mathrm{uL}$. Liver function test was abnormal with aspartate aminotransferase (AST or SGOT) was 135 U/L (normal range 0-50) and alanine aminotransferase (ALT or SGPT) was $112 \mathrm{U} / \mathrm{L}$ (normal range 0-50). 
Renal function test was also abnormal with blood urea nitrogen (BUN) was $30 \mathrm{mg} / \mathrm{dL}$ (normal range 7-18) and creatinine serum was $2.26 \mathrm{mg} / \mathrm{dL}$ (normal range 0.61.3). Based on the Cockcroft-Gault equation, the creatinine clearance was $41.0 \mathrm{~mL} / \mathrm{min}$. Based on the abnormal renal function test and clearance creatinine, this patient was diagnosed with acute kidney injury due to dehydration caused by vomiting. Fasting blood glucose and HbA1C level was above normal, 167 $\mathrm{mg} / \mathrm{dL}$ (normal $<100$ ) and was 9.4\% (normal range 4.5-
6.2 ), respectively. Uric acid was $8 \mathrm{mg} / \mathrm{dL}$ (normal $<7.5$ ). From lipid profile examination, triglyceride level was $544 \mathrm{mg} / \mathrm{dL}$ (normal range 30-150), total cholesterol was $203 \mathrm{mg} / \mathrm{dL}$ (normal <200), HDL level was $9 \mathrm{mg} / \mathrm{dL}$ (normal range 40-60), LDL level was 92 $\mathrm{mg} / \mathrm{dL}$ (normal range 60-99). This patient was also checked for HIV rapid test to look for another immunocompromised condition and the result was nonreactive. Table 1 shows the result of the laboratory examination.
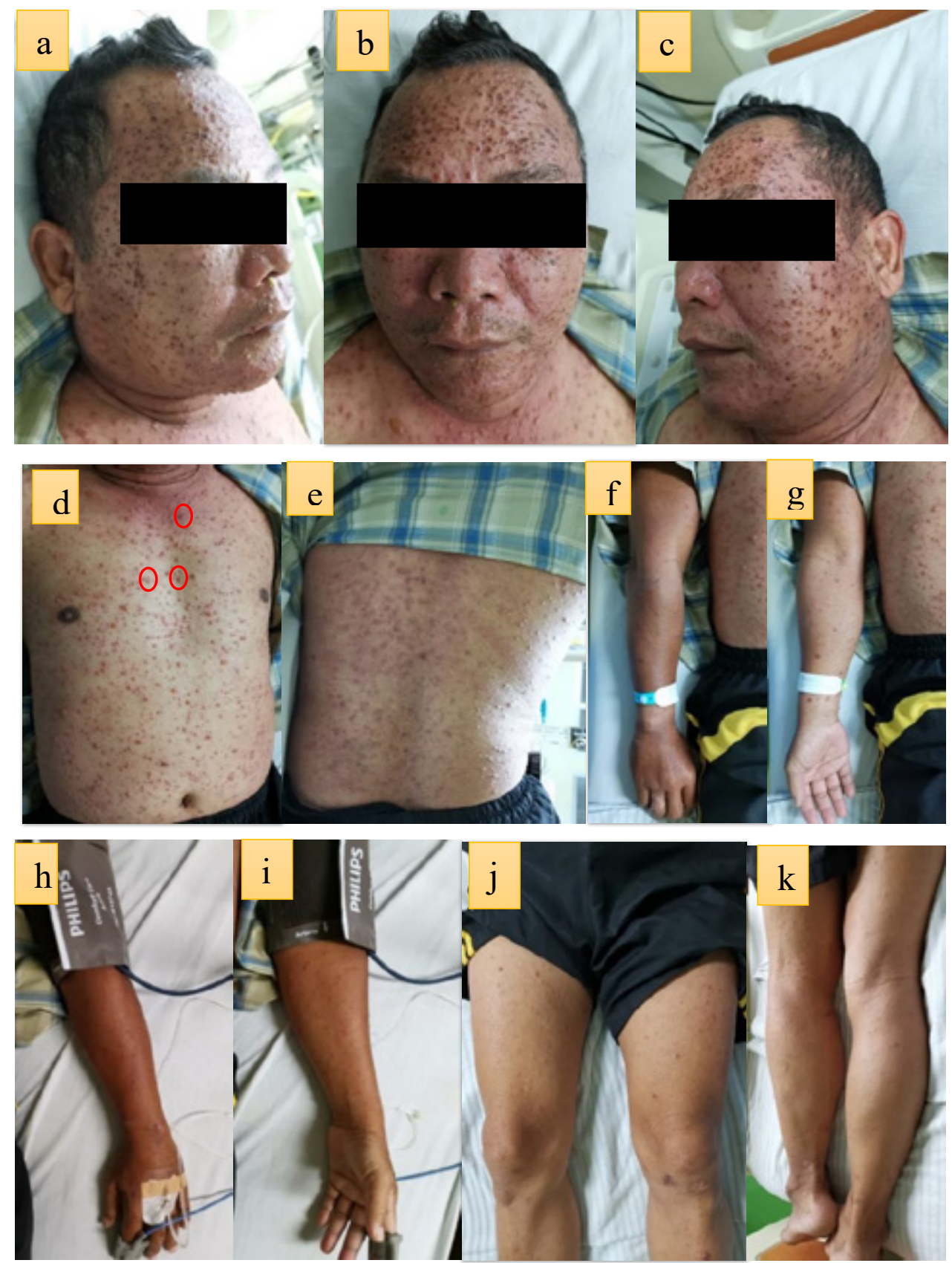

Figure 1. The dermatology status from the initial examination. (a, b, c) on facial region, there were multiple pleomorphic vesicles (multiple stages of development) and multiple crusts. (d, e, f, g, h, i, j, k) on trunk and extremities superior et inferior region, there were multiple pleomorphic vesicles (multiple stages of development) with the centripetal distribution. Note the multiple stages of development of the vesicles and some vesicles with umbilication (red circles). 
Table 1. The progression of laboratory's result from day 2, day 3 and day 8

\begin{tabular}{|c|c|c|c|}
\hline & Day 2 & Day 3 & Day 8 \\
\hline \multicolumn{4}{|l|}{ Complete Blood Count } \\
\hline Hemoglobin & 12.5 & & 8.4 \\
\hline Red blood cells & $4.48 \times 10^{6}$ & & $3.10 \times 10^{6}$ \\
\hline White blood cells & 6,870 & & 6,010 \\
\hline Platelet & 125,000 & & 235.000 \\
\hline \multicolumn{4}{|l|}{ Liver Function Test } \\
\hline AST/SGOT & $135(0-50)$ & 112 & 68 \\
\hline ALT/SGPT & $112(0-50)$ & 90 & 55 \\
\hline HBsAg & & Nonreactive & \\
\hline Anti-HCV & & Nonreactive & \\
\hline Rapid test for HIV & Nonreactive & & \\
\hline \multicolumn{4}{|l|}{ Renal Function Test } \\
\hline BUN & $30(7-18)$ & 31 & 10 \\
\hline Creatinine Serum & $2.26(0.6-1.3)$ & 2.29 & 1.18 \\
\hline Creatinine Clearance & 41.0 & 40.5 & 78.6 \\
\hline \multicolumn{4}{|l|}{ Blood Glucose } \\
\hline Fasting & $167(<100)$ & & \\
\hline 2 hours after the meal & & $198(<140)$ & \\
\hline $\mathrm{HbA1C}$ & $9.4(4.5-6.2)$ & & \\
\hline Uric acid & $8(<7.5)$ & & \\
\hline \multicolumn{4}{|l|}{ Lipid Profile } \\
\hline Triglyceride & $544(30-150)$ & & \\
\hline Total cholesterol & $203(<200)$ & & \\
\hline HDL & $9(40-60)$ & & \\
\hline LDL & $92(60-99)$ & & \\
\hline \multicolumn{4}{|l|}{ Electrolyte Serum } \\
\hline Sodium & $132(136-145)$ & & \\
\hline Potassium & $4.3(3.5-5.1)$ & & \\
\hline Chloride & $95(98-107)$ & & \\
\hline
\end{tabular}

AST: aspartate aminotransferase; SGOT: Serum glutamic oxaloacetic transaminase; ALT: alanine Aminotransferase; SGPT: serum glutamic pyruvic transaminase; HBsAg: hepatitis B surface antigen; HCV: hepatitis $\mathrm{C}$ virus; HbA1C; hemoglobin A1C; HIV: human immunodeficiency virus; HDL: high-density lipoprotein; LDL: low-density lipoprotein

To establish the diagnosis of chickenpox, a tzanck smear and polymerase chain reaction (PCR) examination were done. The vesicle was unroofed and the base was scrapped for tzanck smear examination. With Giemsa staining and 100x objective magnification, a multinucleated giant cell was found (figure 2). PCR examination was done to distinguish this case as chickenpox or monkeypox. The sample for PCR amplification was taken from fluid from the vesicle. A specific primer for VZV was used. The result was positive and matching to positive control in the range of $810 \mathrm{bp}$ (Figure 3). DNA sequencing obtained
(Figure 4) was compared to Nucleotide Sequence Homology Data from the Genbank ${ }^{\circledR}$. From several nucleotides that were compared, it matched with nucleotides for KM355703.1-HHV3-Bandim as much as $99.385 \%$ and nucleotides MH709324-HHV3-USA as much as $99.262 \%$. Whereas the agreement for KJ642616.1-Monkey Pox-Liberia nucleotides only 46.885\%, and NC_003310.1-MonkeyPox nucleotides as much as $46.885 \%$. Based on this data, the diagnosis of chickenpox can be established and the possibility of monkeypox infection in this patient can be ruled out. 


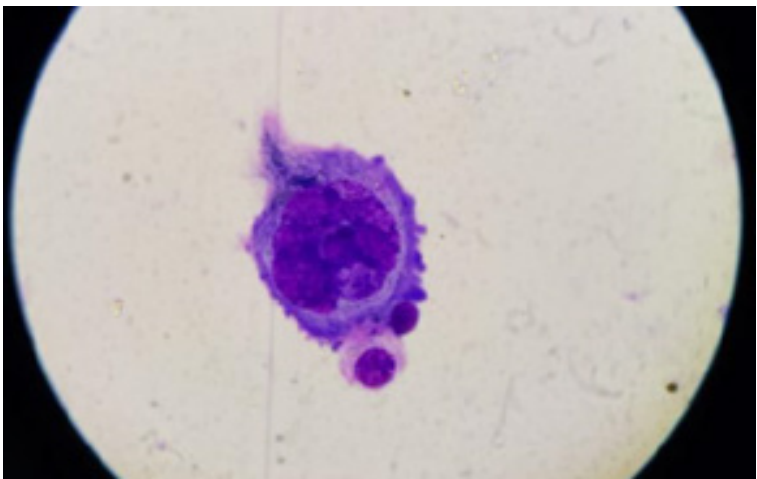

Figure 2. Tzanck smear result with Giemsa staining using objective 100x magnification showing multinucleated giant cell.

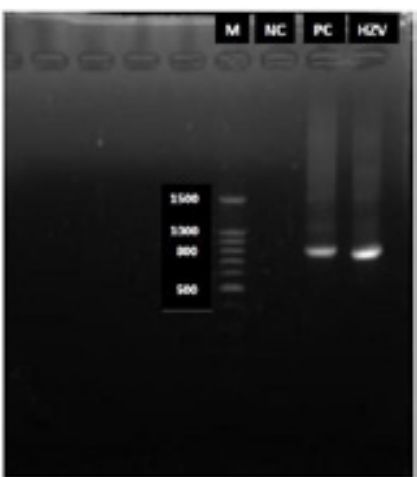

Figure 3. Polymerase chain reaction (PCR) result showing amplicon in range of $810 \mathrm{bp}$. M: marker, NC: negative control, PC: positive control, HZV: herpes zoster virus (Patient).

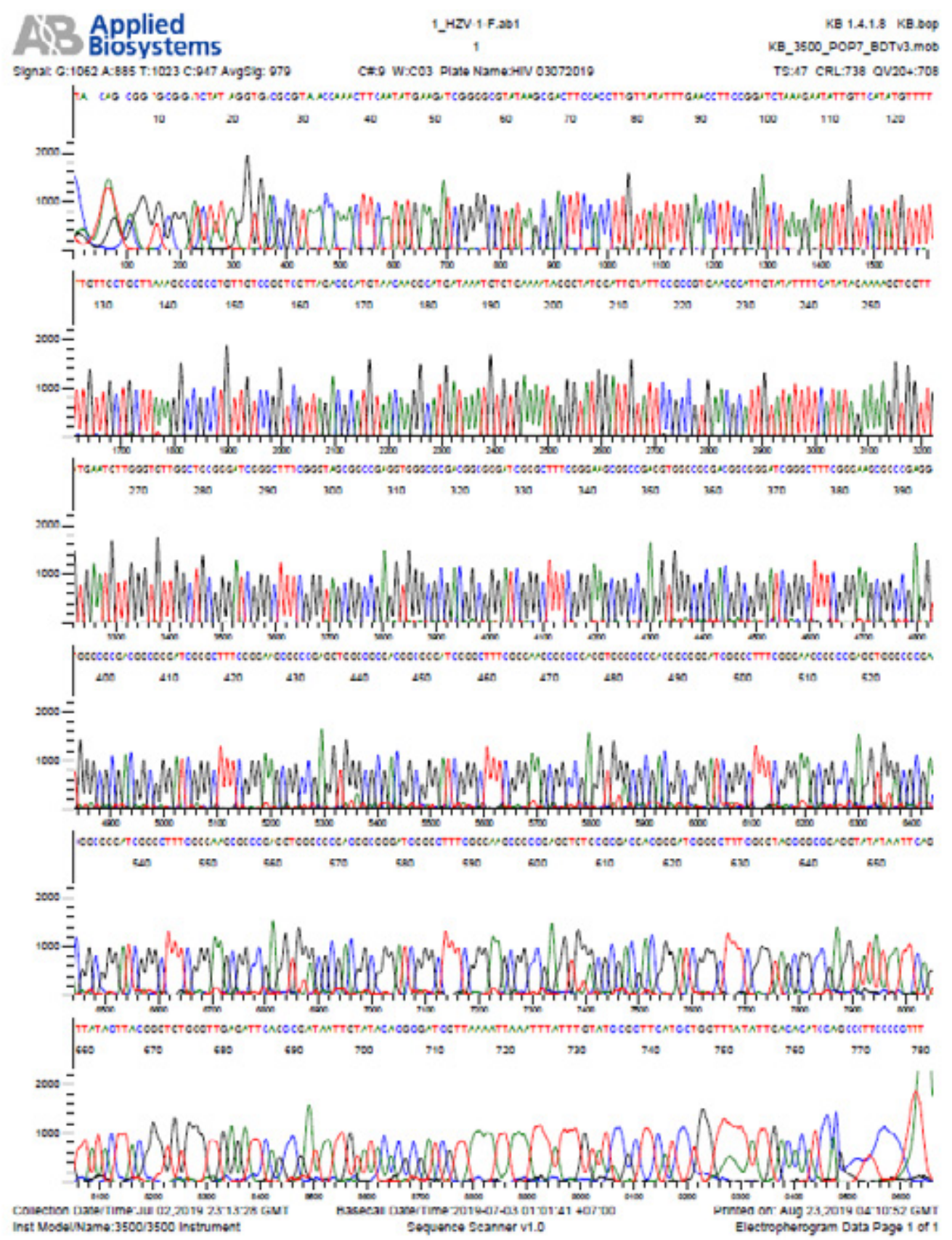

Figure 4. Sequencing result of 810 base pair (bp). 
This patient was assessed with severe chickenpox with diabetes mellitus, acute kidney injury, dyslipidemia, increasing transaminase, and hyperuricemia. He got intravenous (IV) fluid replacement therapy with $\mathrm{NaCl} 0.9 \% 1.000 \mathrm{ml}$ for 24 hours and $1.000 \mathrm{ml}$ fluid per oral. Treatment for severe chickenpox in immunocompromised persons such as in diabetes mellitus is acyclovir $10 \mathrm{mg} / \mathrm{kg}$ IV every 8 hours for 7 to 10 days. This patient got acyclovir 750 mg IV every 8 hours for 3 days. After 3 days of intravenous acyclovir, no new vesicles appeared, the old lesion became crust, liver function test showed improvement. The acyclovir was then switched into oral $800 \mathrm{mg}, 5$ times daily. After a total of 10 days of acyclovir treatment, all the skin lesion became crust, the liver function test became normal, the renal function test and creatinine clearance became normal and the patient was discharged. Table 2 shows the clinical progression and also the patient's treatment. Figure 5 shows the progression of the lesion when the patient was discharged and during the follow-up visit in the outpatient clinic.

Table 2. Clinical progression and treatment

$\begin{array}{llllll}\text { Day } 1 & \text { Day } 2 & \text { Day } 3 & \text { Day } 4 & \text { Day } 5 & \text { Day } 8\end{array}$

Subjective/objective

\begin{tabular}{|c|c|c|c|c|c|c|c|}
\hline Vesicles & +++ & +++ & ++ & ++ & ++ & + & - \\
\hline Crusting & + & + & ++ & +++ & +++ & +++ & +++ \\
\hline Pruritus & +++ & +++ & ++ & ++ & ++ & + & - \\
\hline
\end{tabular}

Therapy

\section{Dermatology and Venereology Division}

\begin{tabular}{|c|c|c|c|c|c|c|c|}
\hline Acyclovir $3 \times 250 \mathrm{mg}$ i.v & $\begin{array}{c}+ \\
\text { (Day 1) }\end{array}$ & & & & & & \\
\hline Acyclovir $3 \times 750 \mathrm{mg}$ i.v & & $\begin{array}{c}+ \\
(\text { Day 1) }\end{array}$ & $\begin{array}{c}+ \\
\text { (Day 2) }\end{array}$ & $\begin{array}{c}+ \\
\text { (Day 3) }\end{array}$ & - & - & - \\
\hline $\begin{array}{l}\text { Acyclovir } 5 \times 800 \mathrm{mg} \\
\text { orally }\end{array}$ & & - & - & $\begin{array}{c}+ \\
(\text { Day 1) }\end{array}$ & $\begin{array}{c}+ \\
\text { (Day 2) }\end{array}$ & $\begin{array}{c}+ \\
(\text { Day } 5)\end{array}$ & $\begin{array}{c}+ \\
\text { (Day 7) }\end{array}$ \\
\hline Cetirizin $10 \mathrm{mg} 1 \mathrm{x} 1$ & + & + & + & + & + & + & + \\
\hline $\begin{array}{l}\text { Paracetamol + N- } \\
\text { acetylcystein } 3 \times 1\end{array}$ & + & + & + & + & + & + & + \\
\hline $\begin{array}{l}\text { Fusidic acid } 2 \% \\
\text { ointment on erosion }\end{array}$ & + & + & + & + & + & + & + \\
\hline
\end{tabular}

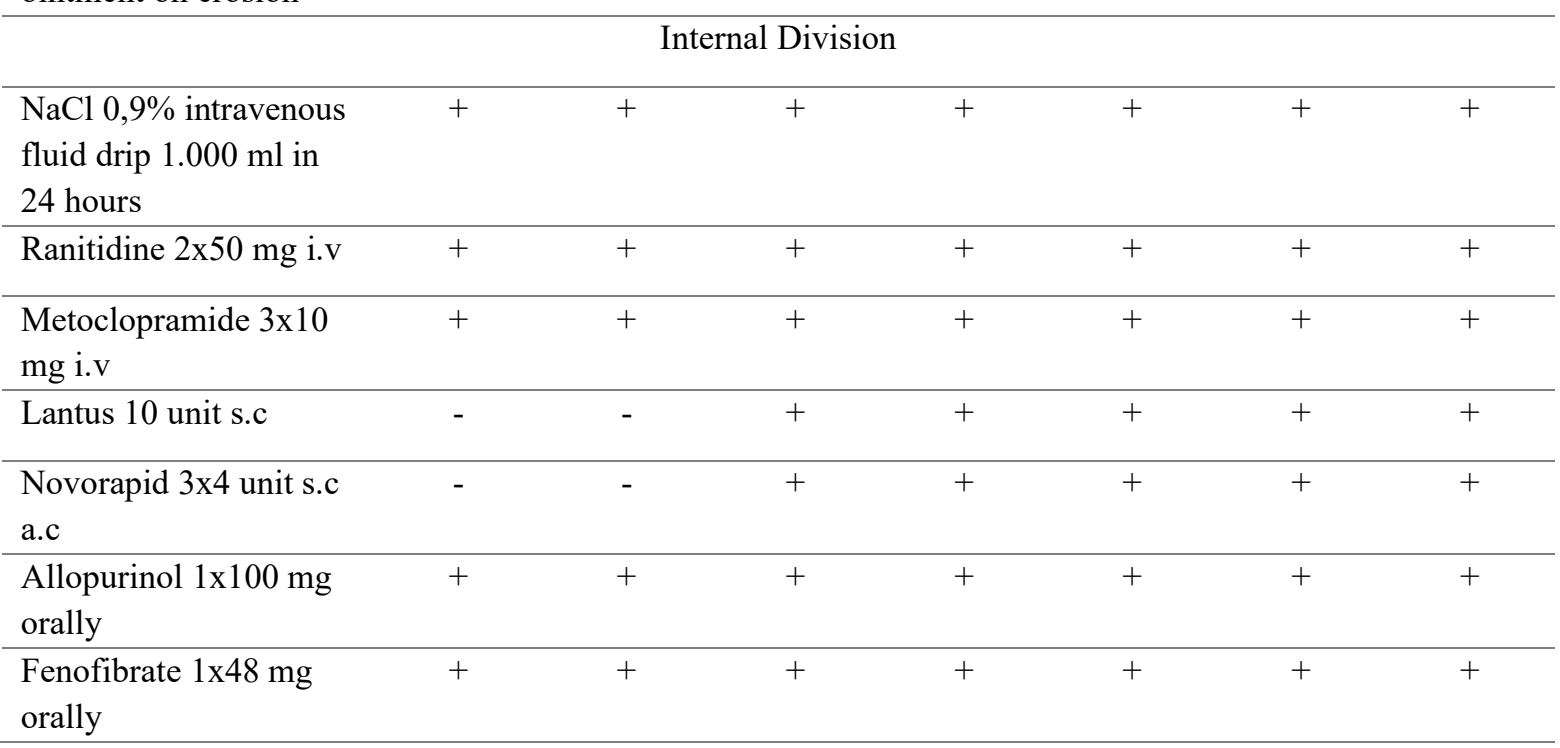

a.c: ante cunam; i.v: intravenous; s.c: subcutis 


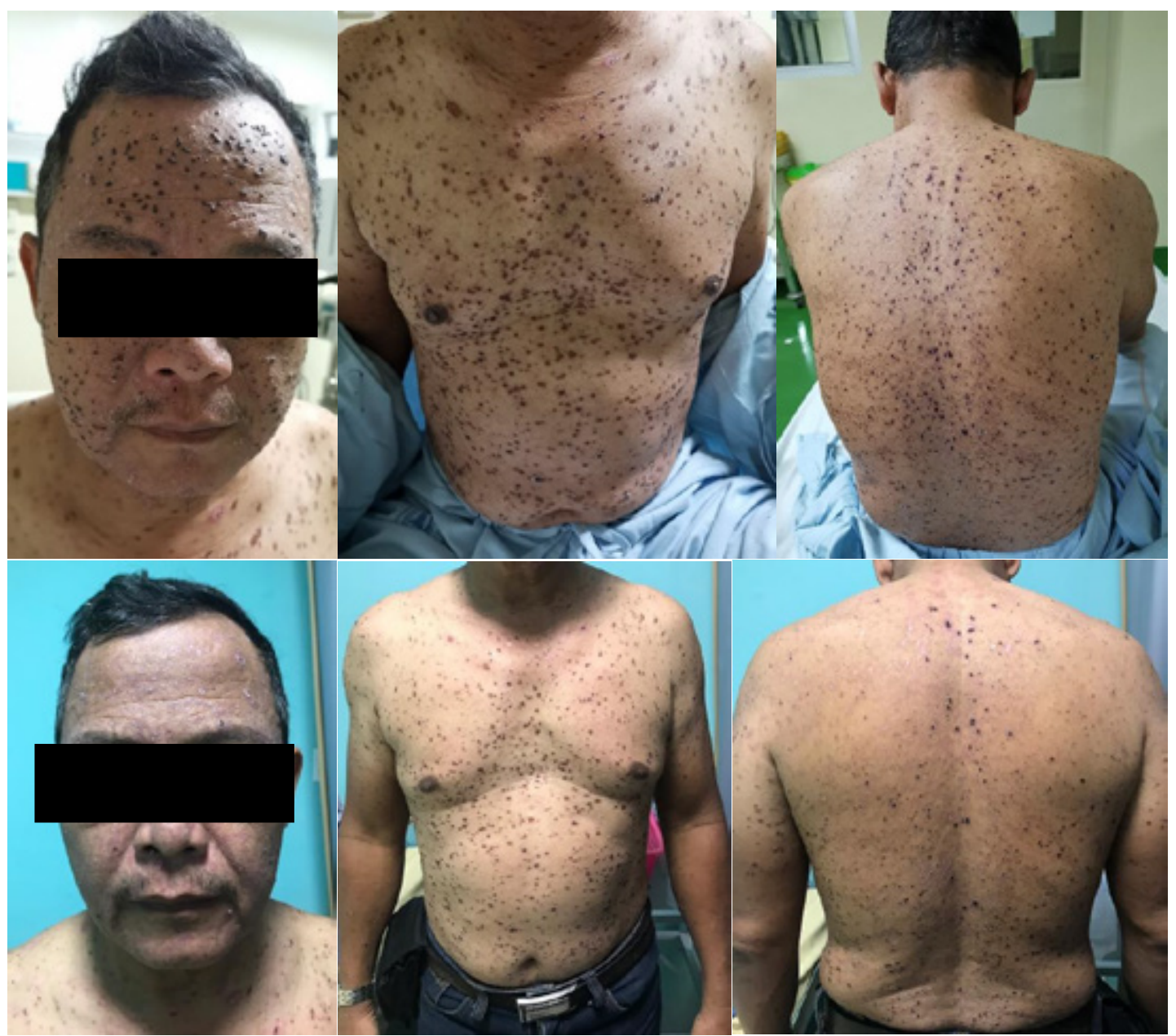

Figure 5. (Top) The progression of the lesion when the patient was discharged on day 10. All the vesicles have become crusts. (Bottom) Progression of the lesion during the follow-up visit in the outpatient clinic three days after discharge. Some of the curst have fallen off.

\section{DISCUSSION}

Chickenpox is typically seen in children 1 to 9 years of age. Primary infection in adults is usually more severe. ${ }^{9}$ Moreover, infection in immunocompromised individuals often causes disseminated disease or nonspecific clinical features. The special risk is in individuals with impaired cellular immune function, such as in patients with diabetes mellitus. Patient with diabetes mellitus significantly has lower cellular mediated immunity to VZV than a healthy individual. ${ }^{4}$ The mechanisms of diabetes-related immune impairment that have been known from numerous studies are suppression of cytokine production, defect in leukocyte recruitment, defect in pathogen recognition, neutrophil dysfunction, macrophage and monocyte dysfunction, MK-cell dysfunction. ${ }^{10}$ This condition can be the risk factor and can cause more severe clinical manifestation. ${ }^{11}$ Older age and poorly controlled diabetes mellitus are the most important risk factors associated with the severity and nonspecific clinical features of chickenpox in this patient.
Clinical features of chickenpox usually begin with the prodrome stage. The rash is often preceded by 2 to 3 days of mild fever, chills, malaise, headache, anorexia, backache, and, in some patients, sore throat and dry cough. After that, the rash begins to appear. In unvaccinated persons, it usually begins on the face and scalp then spread to the trunk, relative sparing the extremities. New lesions are mainly distributed centrally. The lesions have rapid progression, from rose-colored macules to papules, and then to vesicles, pustules, and crusts. Vesicle becomes a pustule, which then dries, begins in the center, which makes an umbilicated pustule. Crusts fall off spontaneously in 1 to 3 weeks. Fever usually persists as long as new lesions continue to appear. Its height is generally proportional to the severity of the rash. Pruritus usually presents until all lesions are crusted. ${ }^{9}$

Monkeypox is an emerging zoonotic disease that can be a differential diagnosis of chickenpox. ${ }^{12}$ Considering a laboratory-confirmed case of monkeypox in Singapore, recognize clinical features of 
monkeypox and distinguish it from chickenpox is important. Table 3 shows the comparison between clinical features of chickenpox, monkeypox, and manifestation in the patient.

Table 3. Clinical features of chickenpox, monkeypox, ${ }^{12,13}$ and manifestation in the patient

\begin{tabular}{llll}
\hline & \multicolumn{1}{c}{ Chickenpox } & Monkeypox & \multicolumn{1}{c}{ Patient } \\
\hline $\begin{array}{l}\text { Recent contact with exotic } \\
\text { animal }\end{array}$ & No & Yes & $\begin{array}{l}\text { Yes (feeding a monkey 1 } \\
\text { week before) }\end{array}$ \\
\hline Time period & $10-21$ days & $7-17$ days & 14 days \\
\hline Incubation & $0-2$ days & $1-4$ days & 1 days \\
\hline Prodromal & 14-28 days & $10-21$ days & 14 days \\
\hline $\begin{array}{l}\text { Rash (appearance to } \\
\text { desquamation) }\end{array}$ & & & \\
\hline
\end{tabular}

\begin{tabular}{|c|c|c|c|}
\hline Symptom & & & \\
\hline Prodromal fever & $\begin{array}{l}\text { Uncommon, mild if } \\
\text { present }\end{array}$ & Yes & Mild \\
\hline Fever & Yes, up to $38,8^{\circ} \mathrm{C}$ & $\begin{array}{l}\text { Yes, often between } 38,5 \\
{ }^{\circ} \mathrm{C} \text { and } 40,5^{\circ} \mathrm{C}\end{array}$ & $\begin{array}{l}\text { No (Patient got } \\
\text { antipyretic) }\end{array}$ \\
\hline Malaise & Yes & Yes & Yes \\
\hline Headache & Yes & Yes & No \\
\hline Lymphadenopathy & No & Yes & No \\
\hline $\begin{array}{l}\text { Lesions on palms and } \\
\text { soles }\end{array}$ & Rare & Yes & No \\
\hline Lesions distribution & Centripetal & $\begin{array}{l}\text { Centrifugal }(80 \%) \text { or } \\
\text { centripetal }(20 \%)\end{array}$ & Centripetal \\
\hline Lesions appearance & $\begin{array}{l}\text { Superficial, irregular } \\
\text { borders, "dew-drop on a } \\
\text { rose petal", umbilicated }\end{array}$ & $\begin{array}{l}\text { Hard and deep, well- } \\
\text { circumscribed, } \\
\text { Umbilicated }\end{array}$ & $\begin{array}{l}\text { Superficial, well- } \\
\text { circumscribed, } \\
\text { umbilicated }\end{array}$ \\
\hline Lesions progression & $\begin{array}{l}\text { Lesions are often in } \\
\text { multiple stages of } \\
\text { development on } \\
\text { the body (pleomorphic ); } \\
\text { fast progression }\end{array}$ & $\begin{array}{l}\text { Lesions are often in one } \\
\text { stage of development on } \\
\text { the body (monomorphic } \\
80 \% \text { ) or pleomorphic } \\
20 \% \text {; slow progression } \\
\text { with each stage lasting } \\
1-2 \text { days }\end{array}$ & $\begin{array}{l}\text { Lesions are in multiple } \\
\text { stages of development } \\
\text { (pleomorphic) }\end{array}$ \\
\hline
\end{tabular}

The general distribution of the fully developed rash of monkeypox is centrifugal $(80 \%)$, with more lesions on the arms and legs than on the trunk, yet $20 \%$ of the cases show centripetal distribution. The palms and soles are commonly affected. However, the rash of chickenpox has a centripetal distribution, with more lesions on the trunk, with the hands and soles exhibiting few or no lesions. In monkeypox, the distinctive lesions often present as first macular, then papular, then vesicular, and pustular. The number of lesions on a given patient may range from a few to thousands. Lesions of monkeypox are often in one stage of development on the body or monomorphic $(80 \%)$, yet $20 \%$ of the cases show pleomorphic development. At some points, monkeypox shows similar characteristics to chickenpox. The appearance of chickenpox in our patient was similar to monkeypox with the characteristic of skin lesions are wellcircumscribed, umbilicated, and numerous lesions. The distribution is centripetal and the progression is pleomorphic which can happen in both monkeypox and chickenpox. Moreover, there was a history of contact with a monkey. When history taking and physical examination are doubtful, diagnostic testing could help to establish the diagnosis.

Tzanck smear and PCR examination were done to establish the diagnosis. Some practical applications of Tzanck smear in dermatological practice are in 
immunobullous diseases, infective diseases including varicella/herpes zoster, genodermatoses, and cutaneous tumors. Tzanck smear is a very simple and rapid technique. For viral infections, samples should be taken from a fresh vesicle, rather than a crusted one, to ensure the yield of several virus-infected cells. The vesicle should be unroofed or the crust removed, and the base scraped with a scalpel or the edge of a spatula. The material is transferred to a glass slide by touching the spatula to the glass slide repeatedly but gently. The slide should be clean since cells will not adhere to a slide marred by fingerprints. Allowed the specimen to air dry and stained with Giemsa stain. ${ }^{14}$ The sensitivity and specificity of tzanck smear for viral infections were respectively $86.36 \%$ and $91.30 \%{ }^{15}$ In this patient, tzanck smear examination from unroofed vesicle showed multinucleated giant cell. Viruses cause abnormal cell division in epidermal cells, and this creates multi-nucleated giant cells. These are epidermal cells that are much larger than normal epidermal cells. ${ }^{16}$ Whereas, there is no literature mentioning the role of tzanck smear as a diagnostic test in monkeypox.

The best diagnostic test for the detection of VZV is polymerase chain reaction (PCR) because of its very high sensitivity and specificity, ready availability, and relatively quick (1 day or less) turnaround time. Vesicle fluid is the best specimen for PCR analysis, but lesion scrapings, crusts, tissue biopsy, or cerebrospinal fluid are equally useful. PCR provides a rapid and accurate means of amplifying DNA therefore PCR can distinguish VZV from HSV, and wildtype VZV from Oka vaccine strains of VZV. PCR requires 4 primary components, which are the thermostable DNA polymerase, nucleotide triphosphates, sample DNA to be amplified, and gene-specific primers. ${ }^{9,17}$

In this case, a VZV primer was used and the result from the patient's sample showed the amplicon matched with the positive control in the range of 810 bp. It was followed by DNA sequencing and the results obtained were compared with Nucleotide Sequence Homology Data from the Genbank $\AA$. GenBank ${ }^{\circledR}$ (http://www.ncbi.nlm.nih.gov) is a comprehensive database that contains publicly available nucleotide sequences for almost 260.000 formally described species. These sequences are obtained primarily through submissions from individual laboratories and batch submissions from large-scale sequencing projects. ${ }^{18}$ From several nucleotides that were compared, it matched with nucleotides for KM355703.1-HHV3-Bandim as much as $99.385 \%$ and nucleotides MH709324-HHV3-USA as much as 99.262\%. Whereas the agreement for KJ642616.1Monkey Pox-Liberia nucleotides only $46.885 \%$, and
NC_003310.1-MonkeyPox nucleotides as much as $46.885 \%$. Based on this data, the possibility of monkeypox infection in this patient can be ruled out and the diagnosis of chickenpox can be established. This result confirmed the infection as VZV which official name is Human Herpes Virus $3^{19}$, instead of on MPXV.

In immunocompetent adults with chickenpox, a randomized, placebo-controlled trial of oral acyclovir showed that early treatment (within 24 hours of rash onset) with oral acyclovir $(800 \pm \mathrm{mg} 5$ times a day for 7 days) significantly reduced the time to crusting of lesions, the extent of disease, and duration of symptoms and fever. ${ }^{2}$ Early treatment (initiated within 24 hours of rash onset) reduced the total time to (100\%) crusting from 7.4 to 5.6 days $(\mathrm{p}=0.001)$ and reduced the maximum number of lesions by $46 \%(p=0.04)$. Duration of fever and severity of symptoms were also reduced by early therapy. ${ }^{20}$ Thus, routine treatment of chickenpox in adults with antiviral is reasonable, especially because chickenpox complications are more frequent in adults. ${ }^{2}$

In immunocompromised patients with chickenpox, controlled trials showed that intravenous acyclovir as the treatment for chickenpox demonstrated the decreasing of life-threatening visceral complications incidence when treatment was initiated within 72 hours of rash onset. A patient who starts IV therapy may be switched to oral therapy when new lesions cease to appear and the patient is stable. The regimen for severe chickenpox or severe immunocompromised is acyclovir $10 \mathrm{mg} / \mathrm{kg}$ IV every 8 hours for 7 to 10 days. $^{2}$

In adults, fever and constitutional symptoms are more prominent and prolonged, the rash of chickenpox is more profuse, and complications are more frequent. A small number of patients develop varicella pneumonia, which is the major severe complication of chickenpox in adults. The morbidity and mortality of chickenpox are markedly increased in immunocompromised patients. In these patients, continued virus replication and dissemination result in a prolonged high-level viremia, more extensive rash, prolongation of new vesicle formation, and clinically significant visceral involvement. Immunocompromised patients may also develop pneumonia, hepatitis, encephalitis, and hemorrhagic complications of chickenpox. ${ }^{2}$

In this case, this patient was hospitalized in a private hospital for 3 days before he was referred. During hospitalization he didn't get either oral or intravenous acyclovir despite this patient was in an immunocompromised condition. After that, his skin lesion got worsen and then he was referred. In Dr. 
Soetomo General Academic Hospital, IV acyclovir 750 mg 3 times daily was given based on his body weight (75 kilograms) and the dosage for severe chickenpox in an immunocompromised patient. The severe skin lesion in this patient might be caused by the late acyclovir treatment besides the immunocompromised condition and older age. The elevated liver function test in this patient might also be a complication from chickenpox considering one of the complications of chickenpox in immunocompromised patients is hepatitis. Even though the clinical manifestation in this patient lasted more than 72 hours, acyclovir was still given considering the extent of skin lesions and elevated liver function test. The presence of new vesicles correlates with recent viral replication and may be a marker for patients who would benefit from antiviral therapy, even beyond 72 hours. In addition, patients presenting with high-risk characteristics such as older age and immunocompromised condition should be considered for antiviral treatment, even when presenting beyond 72 hours after lesion onset. ${ }^{1}$

No specific dosage modification for acyclovir is required for patients with hepatic insufficiency. Acyclovir is cleared primarily by renal mechanisms so dosage modification for acyclovir is required for patients with significant renal dysfunction. The mean elimination half-life of acyclovir after a single 1-gram dose of acyclovir is about 14 hours in patients with endstage renal disease.23 The dosage modification guideline for acyclovir in a patient with end-stage renal disease is available. The modification dosage is given based on the creatinine clearance. For intravenous acyclovir, use normal intravenous dosage every 12 hours if creatinine clearance is $25-50 \mathrm{~mL} /$ minute and every 24 hours if creatinine clearance is $10-25$ $\mathrm{mL} /$ minute. $^{19}$

In this patient, there is no data of the previous creatinine serum, thus it cannot be concluded that the elevation of creatinine serum is a chronic condition. However, considering this patient suffered from vomiting, it could cause dehydration that leads to acute kidney injury. Therefore, in this case, the elevation of creatinine serum and creatinine clearance was most likely caused by reversible pre-renal acute kidney injury. Thus, intravenous and oral acyclovir was given in optimal dosage. The decision was also based on an expert meeting held to manage this patient. In this patient, the creatinine serum and creatinine clearance also became normal after several days of hospitalization and fluid maintenance. After 10 days of hospitalization, this patient showed clinical and laboratory improvement and was discharged from the hospital. Chickenpox in adult and diabetes mellitus patients can give severe clinical manifestation mimicking monkeypox. PCR, although it is not performed routinely, has a significant role to establish the diagnosis especially when it could not be established only from the physical examination. Acyclovir should be given as therapy as soon as possible considering the severity of the disease and condition of the patient.

\section{REFERENCES}

1. Kennedy PGE and Gershon AA. Clinical features of Varicella-Zoster Virus infection. Viruses 2018; 10(11): 609-19.

2. Levin M, Schmader K, Oxman M. Varicella and herpes zoster. In: Kang S, Amagai M, Bruckner AL, Enk AH, Margolis DJ, McMichael AJ, et al., editors. Fitzpatrick's Dermatology. New York: McGraw-Hill Education; 2019. p. 1175-91.

3. Gershon AA, Breuer J, Cohen JI, Cohrs RJ, Mi chael D, Gilden D, et al. Varicella zoster virus infection. Nat Rev Dis Prim 2015; 1(15016): 141.

4. Okamoto S, Hata A, Sadaoka K, Yamanishi K, Mori Y. Comparison of varicella-zoster virusspecific immunity of patients with diabetes mellitus and healthy individuals. J Infect Dis 2009; 200(10): 1606-10.

5. Delaune D and Iseni F. Drug development against smallpox: present and future. Am Soc Microbiol 2020; 64(4): e01683-19.

6. Simpson K, Heymann D, Brown CS, Edmunds WJ, Elsgaard J, Fine P, et al., Human monkeypox - After 40 years, an unintended consequenceof smallpox eradication. Vaccine 2020; 38(33): 5077-81.

7. Sklenovská N, Van Ranst M. Emergence of monkeypox as the most important orthopoxvirus infection in humans. Front Public Heal 2018; 6: 241-52.

8. Harapan H, Setiawan AM, Yufika A, Anwar S, Wahyuni S, Asrizal FW, et al., Knowledge of human monkeypox viral infection among general practitioners: a cross-sectional study in Indonesia. Pathog Glob Health 2020; 114(2): 68-75.

9. Lonsdorf AS, Hadaschik EN. Squamous cell carcinoma and keratoacanthoma. In: Kang S, Amagai M, Bruckner AL, Enk AH, Margolis DJ, McMichael AJ, et al., editors. Fitzpatrick's Dermatology. New York: McGraw-Hill Education; 2019. p. 1901-19.

10. Berbudi A, Rahmadika N, Tjahjadi AI, Ruslami R. Type 2 diabetes and its impact on the immune system. Curr Diabetes Rev 2020; 16(5): 442-9.

11. Sauerbrei A. Diagnosis, antiviral therapy, and prophylaxis of varicella-zoster virus infections. 
Eur J Clin Microbiol Infect Dis 2016; 35(5): 723 34.

12. Petersen E, Kantele A, Koopmans M, Asogun D, Yinka-Ogunleye A, Ihekweazu C, et al., Human monkeypox: epidemiologic and clinical characteristic, diagnosis, and prevention. Infect Dis Clin N Am 2019; 33(4): 1027-43.

13. Wilson ME, Hughes JM, McCollum AM, Damon IK. Human monkeypox. Clin Infect Dis 2014; 58(2): 260-7.

14. Winsett FT, Patel SG, Kelly BC. Bedside diagnostic for inections: a guide for deramtologist. Am J Clin Deramtol 2020; 21(5): 697-709.

15. Yaeen A, Ahmad QM, Farhana A, Shah P, Hassan I. Diagnostic value of tzanck smear in various erosive, vesicular, and bullous skin lesions. Indian Dermatol Online J 2015; 6(6): 381-6.

16. Gupta G, Athanikar SB, Pai V V, Naveen KN. Giant cells in dermatology. Indian J Dermatol
2014; 59(5): 481-4.

17. Garibyan L, Avashia N. Research techniques made simple: polymerase chain reaction (PCR). J Invest Dermatol 2013; 133(3): e6.

18. Benson DA, Cavanaugh M, Clark K, KarschMizrachi I, Lipman DJ, Ostell J, et al. GenBank. Nucleic Acids Res 2013; 41(D1): 36-42.

19. Riedel S, Hobden JA, Miller S, Morse SA, Mietzner TA, Detrick B, et al. Herpesviruses. In: Riedel S, Hobden JA, Miller S, Morse SA, Mietzner TA, Detrick B, et al., editors. Jawetz, Melnick \& Adelberg's Medical Microbiology. New York: McGraw-Hill Education; 2013. p. 473-97.

20. Wallace MR, Bowler WA, Murray NB, Brodine SK, Oldfield EC. Treatment of adult varicella with oral acyclovir: A randomized, placebocontrolled trial. Ann Intern Med 1992; 117(5): 358-63. 